\title{
Understanding patients with asthma and COPD: insights from a European study
}

\author{
*Martyn R Partridge ${ }^{a}$, Roberto W Dal Negro ${ }^{b}$, Dario Olivieric, \\ ${ }^{a}$ Faculty Education Office (Medicine), Imperial College, London, UK \\ ${ }^{\text {b } L u n g ~ D e p a r t m e n t, ~ O r l a n d i ~ G e n e r a l ~ H o s p i t a l, ~ B u s s o l e n g o, ~ V e r o n a, ~ I t a l y ~}$ \\ c Department of Clinical Sciences, University of Parma, Parma, Italy \\ ${ }^{\mathrm{d}}$ Scientific Advisory Board Chiesi Foundation, Parma, Italy
}

Received 3rd February 2011; revised 9th April 2011; further revision 5th May 2011; accepted 6th May 2011; online 9th June 2011

\begin{abstract}
Aims: To understand the needs of people with asthma and COPD, and to identify opportunities for improved care.

Methods: Quantitative questionnaire-based survey performed in five European countries on patients with asthma and COPD. Questionnaires were administered to patients using Computer Assisted Web Interview methodology.

Results: 1022 patients with asthma (UK [ $n=190]$; Germany [ $n=214]$; France [ $n=200]$; Italy [ $n=222]$; Spain [ $n=196])$ and 719 patients with COPD (UK [n=153]; Germany [ $n=147]$; France [n=145]; Italy [n=140]; Spain [n=134]) were enrolled in the study. $32 \%$ of those with asthma and $67 \%$ of those with COPD considered that their condition had a significant effect on their quality of life, and stigma and emotional distress was common. Many expressed concern regarding potential medication side effects or that medicines might lose their effect with time. Major discrepancies between expectations and patient satisfaction with the doctor-patient relationship were observed, including a need to be consulted in the choice of inhalers. Consultations were infrequent, and $75 \%$ of respondents sought additional information beyond that received during consultations - commonly from the internet.

Conclusions: Patient satisfaction was high but information needs were not addressed and the emotional burden of disease is underappreciated.

(C) 2011 Primary Care Respiratory Society UK. All rights reserved.

MR Partridge et al. Prim Care Respir J 2011; 20(3): 315-323

http://dx.doi.org/10.4104/pcrj.2011.00056
\end{abstract}

Keywords asthma, COPD, management, adherence, survey, patient needs

See linked editorial by Kaplan and Small on pg 233

The full version of this paper, with online Appendix,

is available at www.thepcrj.org

\section{Introduction}

Asthma and chronic obstructive pulmonary disease (COPD) are long term respiratory conditions which can influence patients' quality of life (QoL) and represent a significant social and economic burden., ${ }^{1,2}$ Preventing chronic symptoms, minimising exacerbations and the need for unscheduled healthcare, and maintaining acceptable levels of physical activity, are among the goals outlined by international guidelines. ${ }^{3,4}$ Inhaled corticosteroids (ICS) are considered the pillar of asthma management, and their fixed combinations with long-acting $\beta_{2}-$ agonists (LABAs) the treatment of choice for those with moderate or severe disease; ${ }^{3}$ for COPD, however, long-acting bronchodilators are considered central to symptomatic management, with ICS additionally recommended for those with severe disease who have a history of exacerbations. ${ }^{4}$

Whilst pharmacological therapy plays an important role in the management of asthma and COPD, optimisation of communication during consultations and support of patients to allow their informed involvement in the management of their condition are also advocated as key components of asthma and COPD care. ${ }^{3,4} \mathrm{GOLD}$ guidelines state that health education plays a relevant role in smoking cessation for patients with COPD and can also improve skills and the ability to cope with illness, ${ }^{4}$ and

\footnotetext{
* Corresponding author: Professor Martyn R Partridge, Faculty Education Office (Medicine), Imperial College London, Level 1, Sir Alexander Fleming Building, South Kensington Campus, London SW7 2AZ, United Kingdom.

Tel: +44 (0)20 75940937 Fax: +44 (0)20 75949800 E-mail: m.partridge@imperial.ac.uk
} 
there is evidence that education can improve a patient's response to COPD exacerbations. ${ }^{5,6}$ The development of a "partnership" between patients and healthcare professionals may be even more important for asthma (as well as the use of tools such as written action plans) in order to facilitate a guided involvement of patients in self-monitoring and self-management of their own condition. ${ }^{7.8}$ Due to the typical "fluctuating nature" of asthma, this is a long term condition where guided self-management is particularly helpful and a more conscious and active involvement of patients in treatment may also address the issue of low adherence to regular therapy - a common reason for suboptimal asthma control. ${ }^{9.10}$

The first step in implementing optimal communication and educational strategies and achieving the goal of a fruitful partnership with patients is to appreciate their feelings and perceptions about their condition and its treatment, their current relationships with healthcare professionals, and the needs they might consider to be not fully addressed. It is also relevant to understand the level of knowledge exhibited by patients with asthma and COPD about their condition, and which sources they access to gain additional information.

Therefore, the present study was designed to obtain a comprehensive picture of the needs of people with asthma and COPD, to understand what patients consider important for the treatment of their condition, and to identify un-met needs as well as opportunities for providing improved educational tools, optimal communication between patients and healthcare professionals, and, eventually, better therapeutic strategies.

\section{Methods}

This was a quantitative questionnaire-based survey performed in five European countries (UK, Germany, France, Italy and Spain) on patients with asthma and COPD. Questionnaires were administered to patients using Computer Assisted Web Interview (CAWI) methodology.Computer Assisted Telephone Interview (CATI) was used for a portion of COPD patients in order to overcome the potential barrier represented by computer use in the older age group. Questionnaires were prepared based on the results of a preliminary qualitative survey.

\section{Qualitative phase}

The qualitative phase consisted of in-depth individual interviews of 60 minutes, performed with 12 asthma patients and 12 COPD patients in each country (120 patients in total) by researchers specialised in motivational techniques. Due to the reduced sample size of the qualitative phase, general applicability of the results was ensured by recruiting specific quotas of patients with different characteristics in terms of gender, age, socio-economic status, level of asthma control or level of dyspnoea for COPD patients, and geographical spread. The aim of the qualitative phase was to understand patients' language and their levels of knowledge regarding their condition, as well as their experiences, needs and expectations regarding pharmacological interventions and relationships with health care providers. This knowledge was then used to develop the questionnaires used during the quantitative phase, with the questionnaires populated with questions, wording and items which were well known and understood by patients.

\section{Quantitative phase: asthma and COPD questionnaires}

The final questionnaires - one for asthma patients and one for COPD patients - both contained 47 questions and were translated into each language, independently checked and back-translated (see online Appendix 1 at www.thepcrj.org for the English versions of both questionnaires).

Internet interviews (25-30 minutes duration) were conducted by Kantar Health between October and November 2009. Pilot testing of the questionnaires was performed on the first 10 patients in each country before proceeding with questionnaire administration to all the other patients. This step was performed to verify the feasibility of the questionnaires and patients' understanding of all the 47 questions.

\section{Selection of study subjects}

Respondents were selected from a panel of $1,835,000$ prerecruited individuals who had previously agreed to take part in research opinion studies. This panel included patients with a diagnosis of asthma and COPD enrolled through general practitioners (GPs) and specialists in the five European countries. Selection of patients for the present study was performed randomly from individuals with asthma and COPD included in the general panel in each country. An invitation to participate was sent by email to randomly selected individuals whilst a number of elderly patients with COPD were contacted by telephone to counteract bias inherent in the use of email recruitment. Amongst those included in the panels, quotas of patients from each country were recruited to ensure adequate geographical variation. For the asthma sample we also introduced quotas of patients based on age ( $50 \%$ between the ages of 18 and 40 years and $50 \%$ over the age of 40 ) to allow the inclusion of a heterogeneous population. In the COPD sample we only included individuals over 50 years old. Subjects were excluded if they were participating in other studies. Demographic characteristics of the respondents were determined in terms of age, sex, educational level, time since diagnosis and current therapy. All subjects gave written informed consent to the study which was carried out in accordance with Market Research Society guidelines and data protection laws.

\section{Assessment of asthma control and level of dyspnoea of} COPD patients

The Asthma Control Questionnaire (ACQ; 6-item version with forced expiratory volume in one second [ $\left.\mathrm{FEV}_{1}\right]$ question omitted) was used to assess asthma control. .11, $^{12}$ Patients were defined as having well controlled asthma (ACQ score $<0.75$ ), partially controlled asthma (ACQ score between 0.75 and 1.5), or 
uncontrolled asthma (ACQ score > 1.5). ${ }^{13}$

The modified Medical Research Council (MMRC) dyspnoea scale was used to determine the severity of dyspnoea, the hallmark symptom of COPD. Patients were classified as having mild to moderate dyspnoea (MMRC score $<3$ ) or moderate to severe dyspnoea (MMRC score $\geq 3$ ). ${ }^{14}$

\section{Results}

\section{Sample population}

Exact data on response rates following random selection (from among the asthma and COPD patients listed in each country as part of the pre-recruited panel of $1,835,000$ individuals) and invitation to participate are unavailable. However, according to the research company used, of the total number of asthma and COPD patients contacted (most by e-mail but a proportion of COPD patients were contacted by phone), approximately 1 in 4 of the asthma patients and 2 in 4 of the COPD patients expressed their willingness to participate, giving response rates of approximately $25 \%$ and $50 \%$, respectively. A total of 1022 patients with asthma (UK $[n=190]$; Germany $[n=214]$; France $[n=200]$; Italy $[n=222]$; Spain [n=196]) and 719 patients with COPD (UK [n=153]; Germany [ $n=147]$; France $[n=145]$; Italy $[n=140]$; Spain $[n=134]$ ) were finally enrolled in the study.

Demographic data for all patients is shown in Table 1. The mean time since diagnosis was longer for asthma patients than for COPD patients, while the mean age was higher for COPD patients (63 years) than for those with asthma (37 years). The percentage of smokers or ex-smokers differed ( $85 \%$ of the COPD patients and $54 \%$ of the asthma patients) as did the percentage of patients who were taking regular pharmacological therapy at the time of the interview $(76.6 \%$ - COPD; $50.7 \%$ - asthma). Patient characteristics were
Table 1. Demographic characteristics of the respondents

\begin{tabular}{lll} 
& $\begin{array}{l}\text { Asthma } \\
(\mathrm{n}=1022)\end{array}$ & $\begin{array}{l}\text { COPD } \\
(\mathrm{n}=719)\end{array}$ \\
\hline Mean age \pm SD (years) & $36.7 \pm 10.6$ & $62.4 \pm 8.6$ \\
\hline Male (\%) & 30.5 & 56.5 \\
\hline Medium or high educational level (\%) & 73.7 & 46.5 \\
\hline Mean time since diagnosis \pm SD (years) & $15.2 \pm 11.4$ & $6.4 \pm 6.5$ \\
\hline Smokers or ex smokers (\%) & 54.0 & 85.0 \\
\hline $\begin{array}{l}\text { Currently on regular pharmacological } \\
\text { therapy (\%) }\end{array}$ & 50.7 & 76.6 \\
\hline $\begin{array}{l}\text { Uncontrolled asthma (ACQ > 1.5) } \\
\text { Moderate to severe dyspnoea }\end{array}$ & 38.4 & $\mathrm{NA}$ \\
\hline (MRC score $\geq 3)$ & $\mathrm{NA}$ & 35.9 \\
\hline
\end{tabular}

NA: Not Applicable

* Medium educational level: staying on at school until 18 years and obtaining "school leavers certificate" or equivalent. High educational level: university degree or equivalent

consistent across the five national samples (data not shown).

Thirty-eight percent of the patients with asthma were uncontrolled based on the ACQ scores, and $27 \%$ were only partially controlled. $57.8 \%$ of asthma patients reported using at least 1-2 puffs of short-acting bronchodilator most days. Among those with COPD, 36\% had moderate to severe dyspnoea (MMRC score $\geq 3$ ) and $25 \%$ reported at least one hospitalisation due to COPD in the previous year.

Perception of disease severity and emotional aspects When asked to define their condition in their own words, the majority of people with asthma (48.3\%) used expressions related to the most common symptoms (breathing difficulties/dyspnoea), but $23.9 \%$ defined the disease in terms of sensations of fear, distress or bother. $28.6 \%$ of COPD patients referred to symptoms to define their condition, but a

Figure 1. Perception of disease severity among asthma and COPD respondents

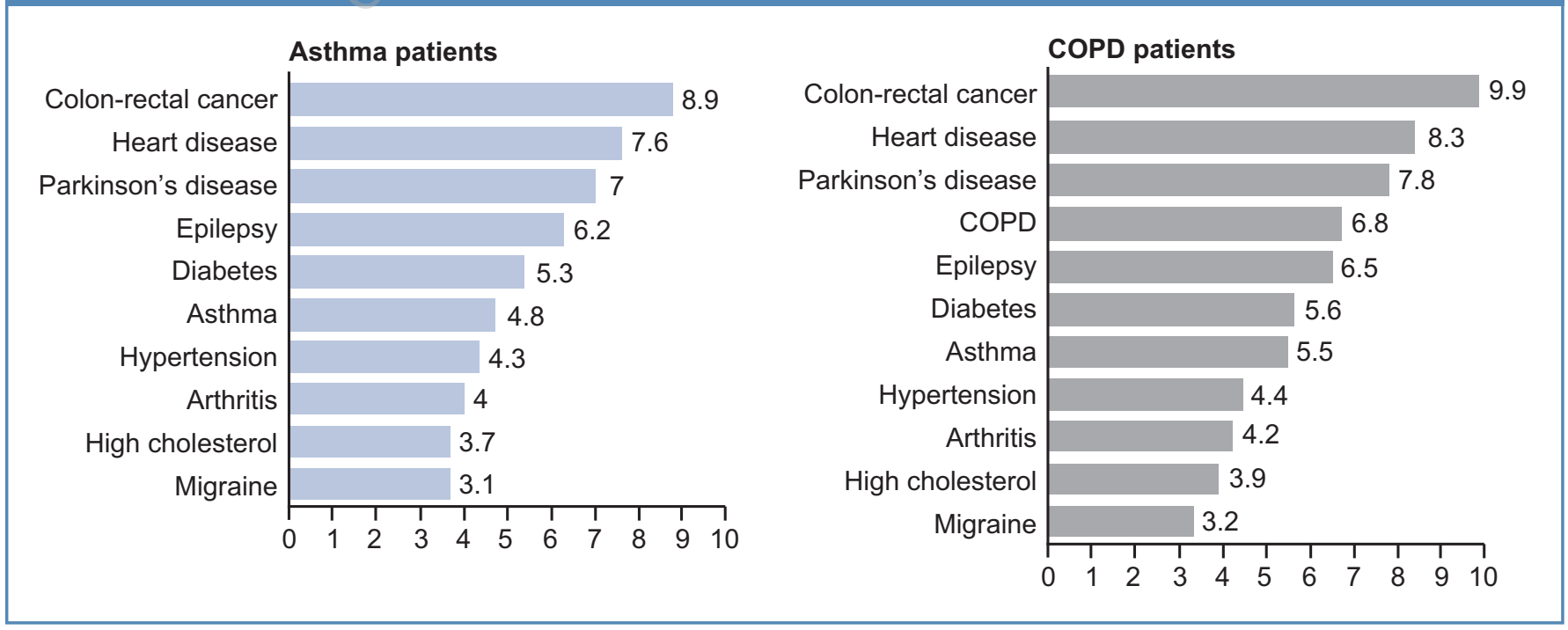


similar percentage $(28.7 \%)$ associated their condition with the sensations of burden, limitation, or disability. Among those with asthma, 32\% reported that their condition had "a lot" or "quite a lot" of negative impact on their QoL, while amongst those with COPD 67\% reported the same degree of negative impact. When offered a choice of 11 diseases, those with COPD ranked COPD as being more serious than epilepsy, asthma, diabetes, hypertension, arthritis, hypercholesterolemia and migraine, with only Parkinson's disease, heart disease and large bowel cancer being regarded as more serious than COPD. Patients with asthma regarded epilepsy and diabetes (as well as Parkinson's disease, heart disease and large bowel cancer) as being more serious than their own condition (see Figure 1). These rankings were independent of the respondents' level of asthma control or of dyspnoea severity (data not shown).

Figure 2 highlights the commonly expressed feelings and concerns expressed by those with asthma and COPD. Fears of seasonal worsening were among the most recurrent concerns: fear of asthma worsening during the pollen season was reported by $54 \%$ of the asthma respondents, and a similar percentage of COPD patients expressed fear of exacerbations in cold weather. $53 \%$ of COPD patients reported that they significantly reduced physical activity for fear of breathing difficulties, and $47 \%$ stated that they had been forced to preplan all of their activities due to COPD. About $20 \%$ of patients with asthma and COPD reported feeling embarrassed at taking their medication in front of other people.

\section{Attitudes towards regular therapy}

Respondents' views regarding regular asthma and COPD therapies are shown in Figure 3. 55.4\% of asthma patients reported adjusting their regular therapy in relation to how they felt; a lower percentage of COPD patients reported the same behaviour. A significant number of respondents expressed concerns regarding possible side effects of regular therapy $(40.6 \%$ of those with asthma and $30.6 \%$ of those with (OPD), or about the possibility that regular therapies might lose their effects after prolonged use. A very high percentage of respondents declared that a regular treatment which provided immediate benefits would promote regular taking of that treatment $(64.2 \%$ of asthma patients and $65.8 \%$ of those with COPD).

\section{Relationship with healthcare professionals}

Fifty-five percent of those with asthma and $71 \%$ of those with COPD reported having follow-up by a specialist, with a

\section{Figure 2. Recurrent problems and concerns reported by asthma and COPD respondents}

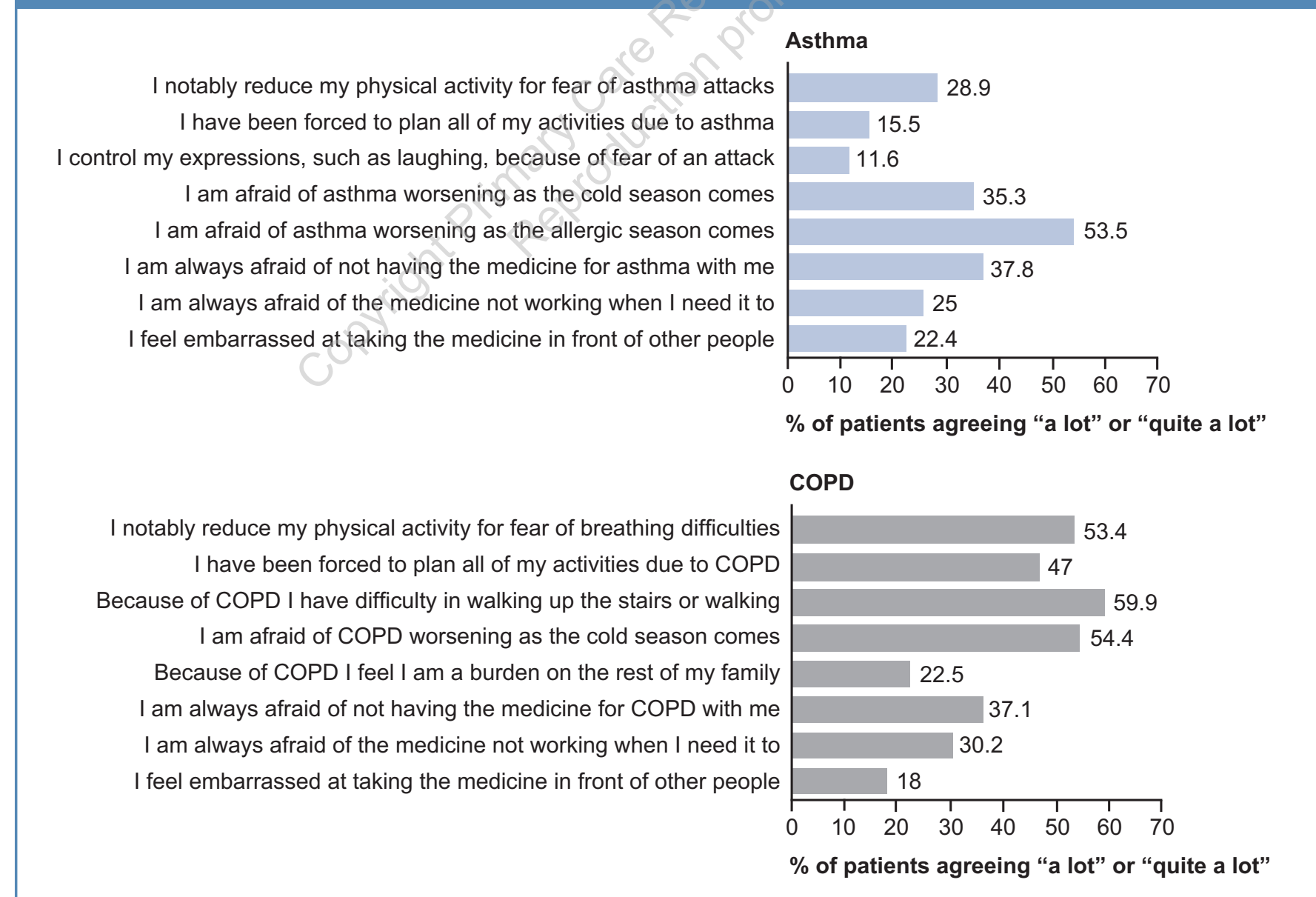


Figure 3. Attitudes and concerns reported by respondents regarding regular asthma and COPD therapies

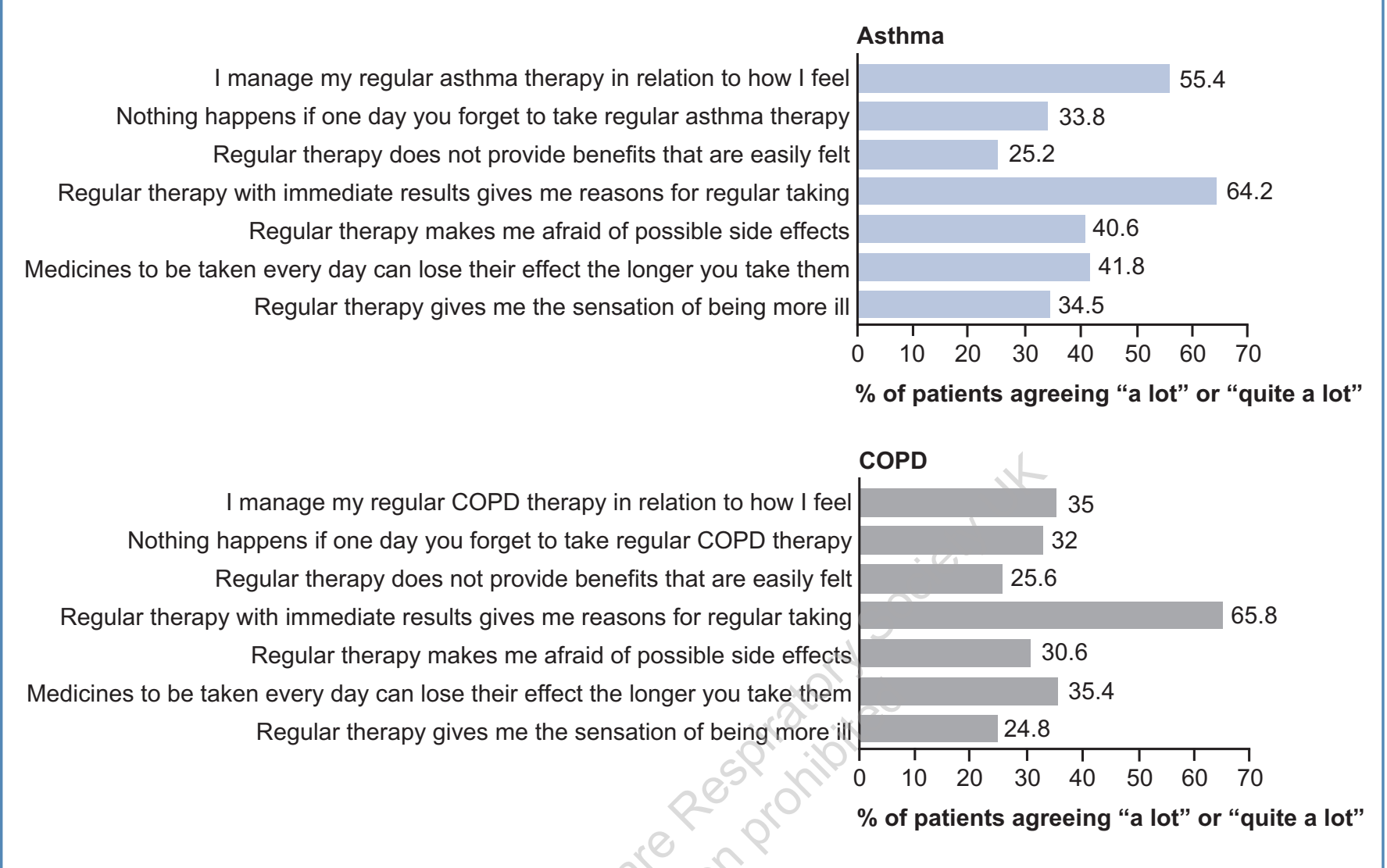

mean frequency of 1.9 years and 7 months, respectively. In the UK, less patients than in other countries reported visits to a specialist (19.8\% of those with asthma and $36.2 \%$ of those with COPD). Visits to GPs for asthma and COPD were reported by $64 \%$ and $67 \%$ of the patients, respectively. The mean frequency of visits due to asthma was 10.4 months; the mean frequency of visit due to COPD was 5.3 months. Both asthma and COPD patients reported mean visit duration of 27 minutes and 16 minutes with specialists and GPs, respectively. Among patients visiting both GPs and specialists, only $50 \%$ of asthma patients and $61 \%$ of those with COPD were aware of contacts or exchanges of information between their GPs and specialists with regard to the management of their condition. This result differed between countries, with patients in Spain and Italy believing that communication between specialists and GPs was much less likely than reported by respondents in other countries.

Figure 4 shows patients' expectations and level of satisfaction, on a scale of 1-10, regarding aspects of their relationship with GPs and specialists during consultations. Both asthma and COPD patients rated "listening carefully when I talk about my symptoms and problems" as their most important need. The other two needs ranked very highly by both asthma and COPD patients were the need for a clear explanation of their condition and a desire for the doctor to allocate sufficient time for the consultation. The biggest discrepancy between the level of importance assigned to a specific need and the level of satisfaction experienced by patients related to receiving clear explanation of the possible side effects/risks of the prescribed medicines, being consulted with regard to the choice of inhaler device, and receiving support to self-manage their condition.

Information sources and role of patient associations When asked about the level of educational support received, all the respondents reported that specialists were more likely than GPs to verify patients' inhalation technique. Nevertheless, overall, only $43.5 \%$ of patients with asthma and $48.5 \%$ of those with COPD were asked to demonstrate inhaler technique by their specialist at the time of prescription. $33 \%$ of asthma patients and $41 \%$ of those with COPD received a written action plan to manage their condition from the specialist, while a lower percentage of patients received written plans from GPs. Written material providing information about the disease was given by specialists to $47.3 \%$ of patients with asthma and $35.6 \%$ of those with COPD, and by GPs to $28 \%$ and $31.1 \%$ of asthma and COPD patients, respectively. Only a few of the respondents $(<10 \%$ ) received recommendations by their specialists or GPs on possible websites where they could find 
Figure 4. Rank order (from 1 to 10) of patients' needs and correspondent level of satisfaction (Needs: $1=$ not at all important; 10 = extremely important. Satisfaction: $1=$ not at all satisfactory; 10 = extremely satisfactory) for patients with asthma (top figure) and COPD (bottom figure)

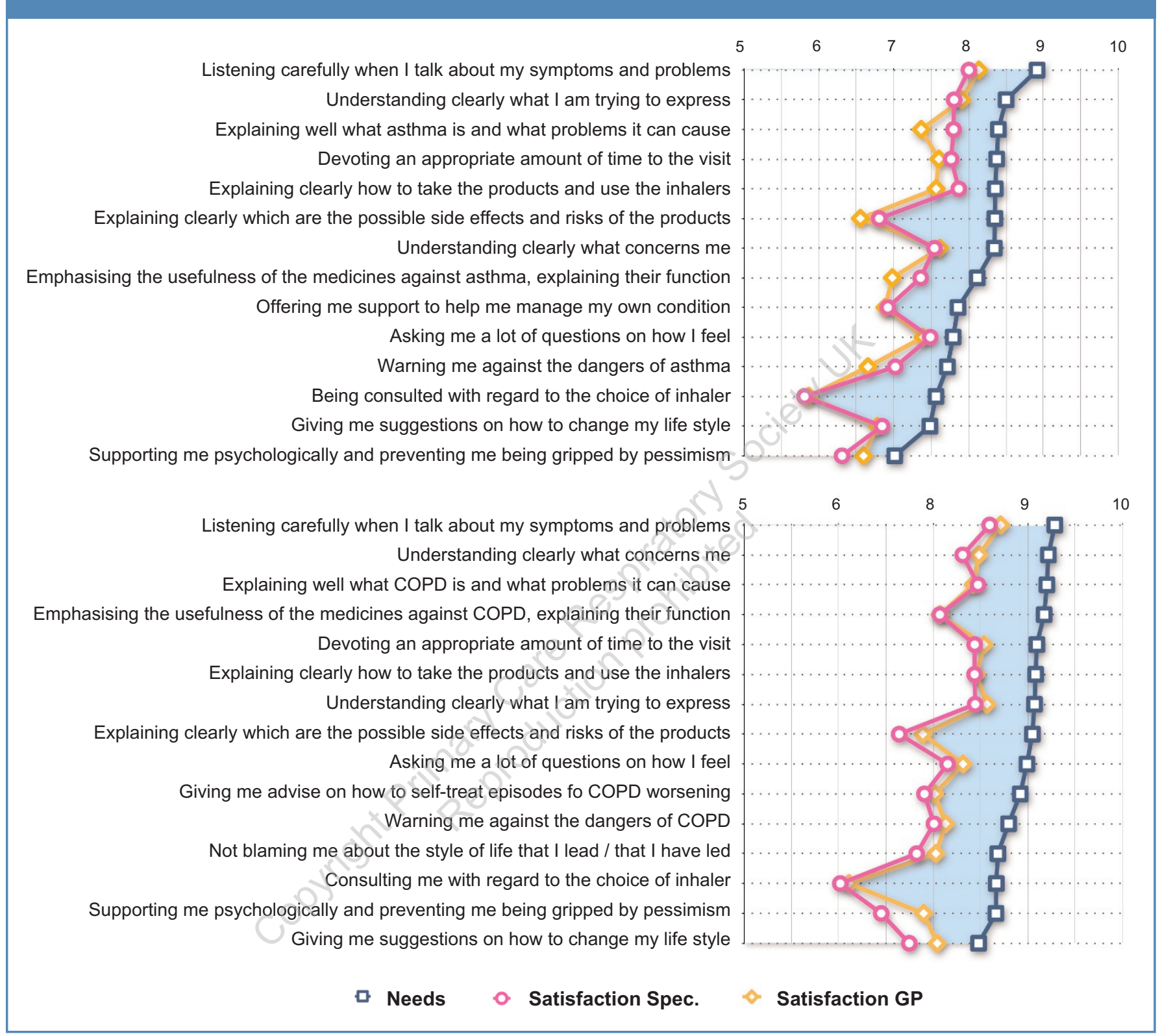

information regarding asthma and COPD.

Only $25 \%$ of people with asthma and $26 \%$ among those with COPD did not seek additional information on their condition and treatments beyond those received during consultations. All others had asked for more information (Figure 5) from their doctors (62\% of those with COPD and $58 \%$ with asthma) and/or had specifically sought information on specific Internet websites/forums (65\% of patients with asthma and $51 \%$ with COPD). In the UK more patients also accessed a nurse for information than in other countries: $27 \%$ of the asthma patients and $40 \%$ of those with COPD.

A third of those on therapy for COPD were aware of patient associations, but only a minority of them (6.6\%) actually joined those associations. The same awareness of patients associations was found in those with asthma, but fewer $(<5 \%)$ actually joined a patient association.

\section{Discussion}

As the burden of respiratory diseases moves from a burden of infectious disease to a burden of long term non-communicable disease, it becomes increasingly important that those caring for patients with respiratory illness take a patient-centred approach. Such an approach involves greater attention being paid to supporting the patient as they manage their own condition, 
Figure 5. Sources accessed by respondents to seek additional information about their condition

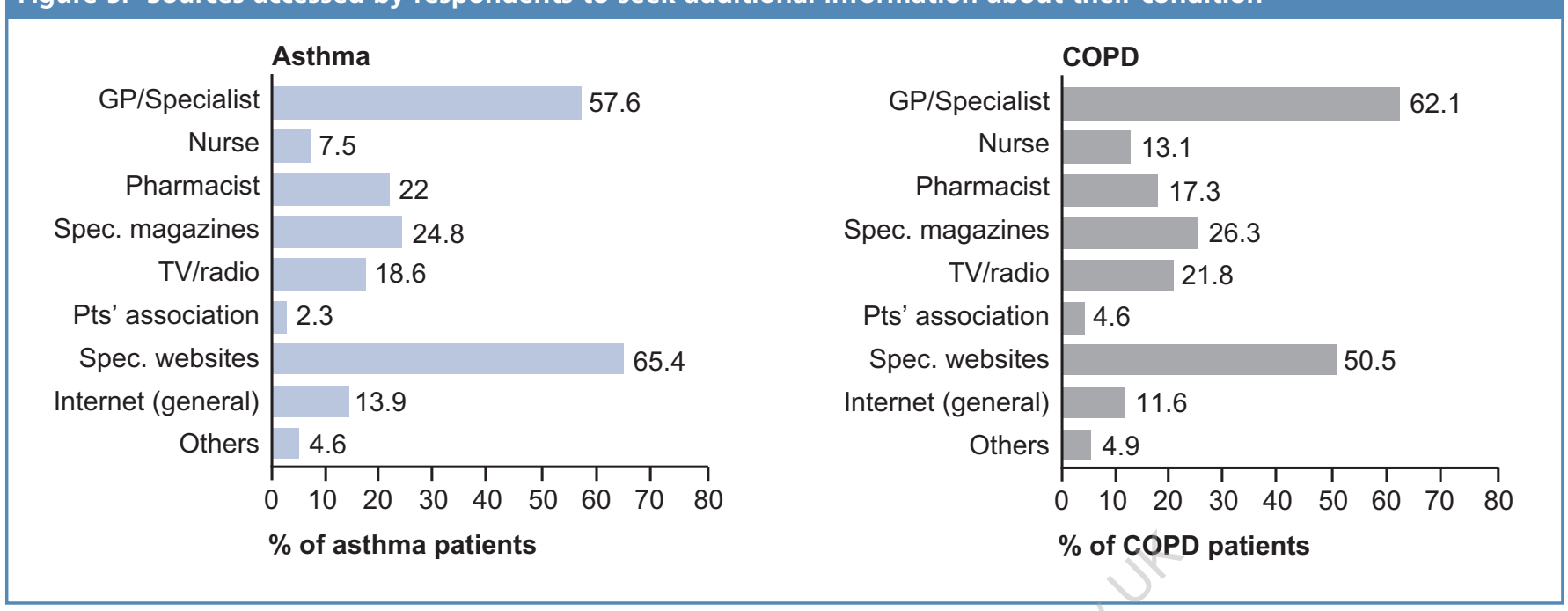

providing convenient follow-up, and (of greatest importance) enhancing adherence by means of optimal communication. The association between patient satisfaction with the communication aspects of consultations and compliance is strong. ${ }^{15}$ Optimal communication entails hearing patients' expectations, eliciting their goals, offering an opportunity for them to express any fears or concerns, and shared decisionmaking regarding on-going management. For long term conditions this process needs to be supported by a process of care that provides convenient follow-up, with the opportunity to reinforce the information offered in an assimilable manner and with easy access to expert healthcare professionals at times of more urgent need.

How do we know this and how is it achieved? Ideally this is an individualised process, but understanding of issues likely to be of importance to those with conditions such as asthma and COPD can be sought from surveys such as that reported here. One of the main limitations of a survey such as this is that the patients surveyed may not be entirely representative of the general disease group. In this survey, the fact that patients were recruited from a panel of $1,835,000$ people who had volunteered themselves for research studies may be a source of bias, as may be the use of the computer-assisted questioning although the latter risk was reduced by providing alternative methods for the elderly. In addition, quite a high percentage of patients recruited in this study had a "medium to high" educational level (see Table 1), so this may be considered a more educated group than the general population. Sampling may also attract those keen on the opportunity to "make their voice known" after having had adverse experiences in the past which they wish to report. Furthermore, surveys such as this are unlikely to include more severe patients. However, despite these limitations, the results reported here seem to be genuine. They seem intuitively correct - with findings that are in keeping with smaller single country studies on certain aspects - and the large number surveyed adds validity.

The study captures significant levels of reported morbidity in asthma and COPD patients; a third of those with asthma and two thirds of those with COPD report an impact of these conditions on their QoL. This is to be expected in COPD due to the absence of interventions able to modify (to any great extent) the progressive lung function decline typical of this condition; but it is also true for asthma, even though very effective medications are available and ambitious goals have been defined by guidelines. Indeed, asthma control was suboptimal in the majority of asthma patients enrolled in the present study. This finding, in a heterogeneous population of asthma patients, is in line with previous studies recording high levels of morbidity both in mild asthma patients with low level of ICS maintenance therapy $^{16-18}$ and in patients receiving daily maintenance therapy with ICS or ICS/LABA. ${ }^{19}$

The data demonstrate that asthma and COPD continue to constitute a significant emotional burden for patients. In particular, those with asthma report fears of seasonal worsening or concerns related to either forgetting to take their medicine with them, or having the medicine not working when they need it to. Many of these fears are shared with COPD patients. However, COPD differs from asthma due to its potential to affect all the aspects of daily life because of the significant impairment of physical activity experienced by patients. The global burden associated with COPD is confirmed; when asked to define their condition, about a third of COPD respondents identified it with the sensations of burden, limitation and disability. The impairment in daily activities and the progressive nature of COPD led patients to rank it as fourth in terms of severity among 11 proffered conditions.

It is disappointing still to find a significant sense of stigma regarding taking of medicines in front of other people, as 
reported by about $20 \%$ of asthma and COPD respondents. This suggests that great effort is still needed to optimise patients' medical education, but also to improve public levels of awareness about chronic respiratory conditions and their treatments.

More than half of the asthma respondents reported adjusting their regular therapy in relation to how they feel. This confirms that (in the absence of symptoms) low adherence to regular medications is an issue, and without properly designed educational strategies the achievement of optimal asthma control may become an elusive goal. ${ }^{9,10,20,21}$ Nevertheless, patients' propensity to take control of their own therapy may be exploited to implement strategies that should lead to a guided involvement of patients in self-monitoring and self-management of their condition, as suggested by guidelines. ${ }^{3}$ Indeed, previous studies have shown that patients are able to recognise deteriorating asthma control but that they usually adjust their medication in an inappropriate manner. ${ }^{19}$

More surprising is the finding that a third of COPD patients also tend to adjust their therapies in relation to the symptoms they experience. As already suggested by previous studies, ${ }^{20}$ it follows that low adherence can represent a significant barrier to optimal management not only for a condition with relatively symptom-free (or "silent") periods like asthma, but also in COPD. This study also highlights the need to address during consultations the concerns and misconceptions patients may have regarding regular therapy, including fear of side effects or fear that regular therapies might lose their effect with prolonged use. The high percentage of respondents who declared that regular treatments which provide immediate benefits reinforce the need to take the medication confirms the results of previous studies in asthma patients. ${ }^{19,21}$

Of concern is the fact that almost half of the respondents were not aware of exchanges of information between GPs and specialists regarding the management of their condition. If such a perception is reality, the opportunity for conflicting messages is significant.

All the patients emphasised their desire for doctors who listened, and for more information regarding their disease and associated problems. This obviously requires time, and devoting an appropriate amount of time to the consultation was another relevant need expressed by all respondents. However, contrary to the findings reported previously which showed doctors' tendency to not always listen, ${ }^{22}$ the respondents recruited in the present study showed a good level of satisfaction (scores $>7$ in a 0 to 10 scale) regarding these areas of their relationship with doctors. Lower levels of satisfaction, on the other hand, were assigned to the psychological support received and to the adequacy of explanation of possible side effects and risks associated with use of prescribed drugs. Addressing the latter need could be particularly relevant to increase adherence to regular therapy, since concerns of side effects were reported by a high percentage of respondents and may act as a barrier to adherence, particularly for those with asthma. ${ }^{23}$ Finally, the lowest level of satisfaction was reported by those with asthma and COPD regarding the possibility of being consulted in the choice of their inhaler. Even though a lot of evidence is available to support the importance of testing patient preference for one type of device over another, and the relevance to teach and verify inhalation technique, ${ }^{24}$ these aspects of care seem to be largely underestimated. Indeed, less than half of our respondents were asked to demonstrate inhaler technique at the time of prescription.

In agreement with previous studies ${ }^{25}$ and in contrast with the recommendations of international guidelines, ${ }^{3}$ the receipt of personal, written, asthma action plans was reported by only a minority of patients. This is of concern because reviews of patients with asthma and COPD by GPs or specialists are infrequent, ranging from once to twice a year for most of the respondents. Most patients self-manage their own condition most of the time and healthcare providers have the responsibility to give them the tools, support and knowledge necessary to do so satisfactorily. Interestingly, a higher percentage of patients with COPD reported having been provided with written selfmanagement plans compared to those with asthma. Indeed, optimisation of self-management in COPD can be extremely relevant because patient early recognition of exacerbation and prompt therapy have been shown to improve exacerbation outcomes. ${ }^{5}$ Furthermore, patients with lower self-management capacity showed higher hospitalisation rates compared to patients with better self-management capacity. ${ }^{6}$

We found that three-quarters of patients with asthma and COPD have a propensity to look beyond the consultation for further information. Although doctors remain a major reference point, patients access a variety of other sources - and the internet was by far the commonest. Surprisingly, this was not only true for the younger population of asthma patients, but it was also the case for older patients with COPD. Even though the CAWI methodology applied in this study may have determined a patient sample particularly familiar with computer and internet use that may partially explain these results, exploiting internet resources more efficiently seems to be a significant opportunity for healthcare providers. Despite a majority of patients reporting that they looking at specialised websites, only a few of those enrolled in the present study declared having received recommendations from their doctors on websites to be consulted

\section{Conclusions}

Despite the availability of potentially effective medications, the results of the present study still show significant emotional 
burden and impairment of QoL both in those with asthma and COPD. Patient attitudes toward regular maintenance therapy suggest that low adherence to prescribed medication - a reason for poor clinical outcomes - could be helped by addressing patients' fears and misconceptions about medicines during consultations. Other opportunities to improve the current level of care for patients with chronic respiratory conditions are the implementation of self-management education, higher involvement of patients during the choice of the inhaler device, and appropriate training and regular checking of their inhalation technique. Although doctors remain a major source of information for patients, the majority of those with asthma and COPD reported a propensity to look beyond the consultation for further information on their condition. Guiding patients to reliable websites and patient support organisations may represent an effective way to increase their educational level and skills so that they can collaborate effectively with healthcare professionals in the management of their condition.

\section{Acknowledgements}

We thank Alessio Amadasi and Serena Paciotti from Chiesi Farmaceutici S.p.a. for editorial support during the preparation of the manuscript.

\section{Conflicts of interest}

Martyn Partridge has received honoraria for lecturing or ad hoc consultancies from AstraZeneca, Chiesi, GSK, Boehringer, Cipla, Novartis, Dr Reddys Laboratories, German Remedies and Teva. He has received research support from AstraZeneca and financial assistance with the production of a book on the history of asthma charities from Novartis.

Roberto Dal Negro has no conflict of interest to declare.

Dario Olivieri has received honoraria for lecturing or ad hoc consultancies from AstraZeneca, Chiesi, GSK, Menarini, MSD,Novartis, Nycomed, OM-Pharma, PierreFabre, Sigma-Tau, Boehringer Ingelheim and Pfizer. He has received research support from AstraZeneca, GSK, MSD, Novartis, Nycomed, OM-Pharma, Zambon, Chiesi, Italian Ministry of Health and Italian Ministry for University and Research. He is a member of the Scientific Advisory Board of the Chiesi Foundation.

\section{Funding}

The survey was carried out by Kantar Health and supported by Chiesi Foundation.

\section{References}

1. Masoli M, Fabian D, Holt S, Beasley R. The global burden of asthma: executive summary of the GINA Dissemination Committee report. Allergy 2004; 59:469-78. http://dx.doi.org/10.1111/j.1398-9995.2004.00526.x

2. Lopez AD, Shibuya $K$, Rao $C$, et al. Chronic obstructive pulmonary disease: current burden and future projections. Eur Respir J 2006;27:397-412. http://dx.doi.org/10.1183/09031936.06.00025805

3. Global Initiative for Asthma: Global strategy for asthma management and prevention (updated 2009). Available from http://www.ginasthma.org

4. Global Initiative for Chronic Obstructive Lung Disease: Global strategy for diagnosis, management and prevention of COPD (updated 2009). Available from: http://www.goldcopd.org

5. Wilkinson TM, Donaldson GC, Hurst JR, Seemungal TA, Wedzicha JA: Early therapy improves outcomes of exacerbations of chronic obstructive pulmonary disease. Am J Respir Crit Care Med 2004; 169:1298-303. http://dx.doi.org/ 10.1164/rccm.200310-14430C
6. Bourbeau J, Julien M, Maltais F, et al. Reduction of hospital utilization in patients with chronic obstructive pulmonary disease: a disease-specific self-management intervention. Arch Intern Med 2003;163:585-91.

7. Partridge MR, Hill SR: Enhancing care for people with asthma: the role of communication, education, training and self-management. 1998 World Asthma Meeting Education and Delivery of Care Working Group. Eur Respir J 2000, 16:333-48.

8. Horne R, Price D, Cleland J, et al. Can asthma control be improved by understanding the patient's perspective? BMC Pulm Med 2007;7:8. http://dx.doi.org/10.1186/1471-2466-7-8.

9. Howell G. Nonadherence to medical therapy in asthma: risk factors, barriers and strategies for improving. Journal of Asthma 2008;45:723-9.

10. Lasmar L, Camargos $P, C$ hamps NS, et al. Adherence rate to inhaled corticosteroids and their impact on asthma control. Allergy 2009;64:784-9. http://dx.doi.org/10.1111/j.1398-9995.2008.01877.x

11. Juniper EF, O'Byrne PM, Guyatt GH, Ferrie DR. Development and validation of a questionnaire to measure asthma control. Eur Respir J 1999;14:902-07.

12. Juniper EF, Svensson K, Mork AC, Ståhl E. Measurement properties and interpretation of three shortened versions of the asthma control questionnaire. Respir Med 2005;99:553-8. http://dx.doi.org/10.1016/j.rmed.2004.10.008.

13. Juniper $E F$, Bousquet J, Abetz L, Bateman ED, the GOAL Committee. Identifying 'well-controlled' and 'not well-controlled' asthma using the Asthma Control Questionnaire. Respir Med 2006;100:616-24. http://dx.doi.org/10.1016/ j.rmed.2005.08.012

14. American Thoracic Society. Surveillance for respiratory hazards in the occupational setting. Am Rev Respir Dis 1982;126:952-6.

15. Apter AJ, Reisine ST, Affleck G, Barrows E, Zuwallack RJ. Adherence with twicedaily dosing of inhaled steroids. Socioeconomic and health-belief differences. Am J Respir Crit Care Med 1998;157:1810-17

16. Rabe KF, Vermeire PA, Soriano JB, Maier WC. Clinical management of asthma in 1999: the Asthma Insights and Reality in Europe (AIRE) study. Eur Respir J 2000; 16:802-07.

17. Price D, Ryan D, Pearce L, Bride F. The AIR study: asthma in real life. Asthma J 1999; 4:74-8.

18. De Marco R, Cazzoletti L, Cerveri I, et al. ISAYA Study Group. Are the asthma guideline goals achieved in daily practice? A population-based study on treatment adequacy and the control of asthma. Int Arch Allergy Immunol 2005;138:225-34. http://dx.doi.org/10.1159/000088723

19. Partridge MR, van der Molen T, Myrseth SE, Busse WW. Attitudes and actions of asthma patients on regular maintenance therapy: the INSPIRE study. BMC Pulm Med 2006;13:6:13. http://dx.doi.org/10.1186/1471-2466-6-13

20. Haupt D, Krigsman K, Nilsson JL. Medication persistence among patients with asthma/COPD drugs. Pharm World Sci 2008;30:509-14. http://dx.doi.org/10.1007/s11096-008-9197-4

21. Haughney J, Fletcher M, Wolfe S, Ratcliffe J, Brice R, Partridge MR. Features of asthma management: quantifying the patient perspective. BMC Pulm Med 2007; 7:16-24. http://dx.doi.org/10.1186/1471-2466-7-16

22. Beckman H, Frankel R. The effect of physician behaviour on the collection of data. Ann Intern Med 1984;101:692-6.

23. Choi TN, Westermann H, Sayles W, Mancuso CA, Charlson ME. Beliefs about asthma medications: patients perceive both benefits and drawbacks. J Asthma 2008;45:409-14. http://dx.doi.org/10.1080/02770900801971834

24. Virchow JC, Crompton GK, Dal Negro R, et al. Importance of inhaler divices in the management of airway disease. Resp Med 2008;102:10-19. http://dx.doi.org/10.1016/j.rmed.2007.07.031

25. Haughney J, Barnes G, Partridge M, Cleland J. The Living \& Breathing Study: a study of patients' views of asthma and its treatment. Prim Care Respir $J$ 2004;13:28-35. http://dx.doi.org/10.1016/j.pcrj.2003.11.007 
MR Partridge et al.

Appendix

\section{PEOPLE WITH ASTHMA - SURVEY}

Gender of respondent: Male 1 Female 2

Introduction

Dear Sir / Madarn,

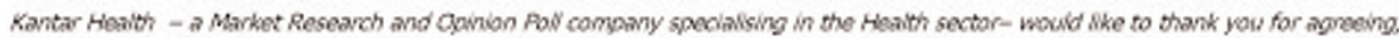
through Dr. ........, to take part in ow survey an asthung sufferers

Are you wiling to take part in the inderview? YES NO

Win regard to our study, please be advieed thit.

- The answers that you give during the interview wiv remain strictly canifidentiac your name and the answers that you give will never be diviged to third parties linking then to your name.

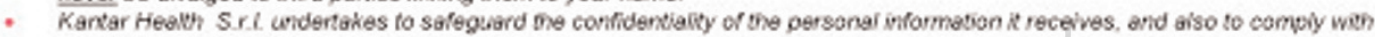
the provisions of low $196 / 2003$ cancerning the handivg of personal data.

- The party responsibie for the treatment of the data is Kantar Heach S.r.

How old are you?

Gender of respondent Male 1 Female 2

Educational qualifications: Secondary School Leaver (G.C.S.E level or equivalent)

Higher Education (A-Level or equivalent)

University DegreerDiploma + (or equivalent)

SCREENING

\section{S.1 Which of the following pathologies do you have?}

Asthma

Psoriasis

Hearth diseases

Diabetes

Kidney failure

COPD / Chronic-obstructive bronchitis

High Blood Pressure

Allergic rhinitis / Hay fever

Osteoporosis

Liver diseases

Gastric ulcer

Ulcerous colitis

Mgraine

Anxiety / Depression

Arthritis

Parkinson's disease

Thyroid diseases

Haemorrhcids

High chalesteral

Epilepsy 


\title{
CLINICAL SITUATION AND HISTORY
}

\author{
IF ASTHMA \\ Do you suffer from allergies? \\ Smoker ? \\ Yes, the whole year round \\ Yes, in the Spring Yes, in the Summer \\ No \\ Current smoker \\ Ex-smoker Non-smoker/Never smoked
}

\begin{tabular}{|c|c|}
\hline $\begin{array}{l}\text { C1. On average, during the pas week, how of ten were you woken by your } \\
\text { asthma during the night? }\end{array}$ & $\begin{array}{l}0 \text { Never } \\
1 \text { Hardly ever } \\
2 \text { A few minutes } \\
3 \text { Several times } \\
4 \text { Many times } \\
5 \text { A great many times } \\
6 \text { Unable to sleep because of asthma }\end{array}$ \\
\hline $\begin{array}{l}C 2 . \text { On average, during the past week, how bad were your asthma symptoms } \\
\text { when you woke up in the morning? }\end{array}$ & $\begin{array}{l}0 \text { No symptoms } \\
1 \text { Very mild symptoms } \\
2 \text { Mild symptoms } \\
3 \text { Moderate symptoms } \\
4 \text { Quite severe symptoms } \\
5 \text { Severe symptoms } \\
6 \text { Very severe symptoms }\end{array}$ \\
\hline $\begin{array}{l}\text { C3. In general, during the past week, how limited were you in your activities } \\
\text { because of your asthma? }\end{array}$ & $\begin{array}{l}0 \text { Not limited at all } \\
\text { (1) Very slightly limited } \\
2 \text { Slightly limited } \\
3 \text { Moderately limited } \\
4 \text { Very limited } \\
5 \text { Extremely limited } \\
6 \text { Totally limited }\end{array}$ \\
\hline $\begin{array}{l}\text { C4. In general, during the past week, how much shortness of hreath did sou } \\
\text { experience because of your asthma? }\end{array}$ & $\begin{array}{l}0 \text { None } \\
1 \text { A very little } \\
2 \text { A little } \\
3 \text { A moderate amount } \\
4 \text { Quite a lot } \\
5 \text { A great deal } \\
6 \text { A very great deal }\end{array}$ \\
\hline C5. In general, during the past week, how much of the lime did you wheeze? & $\begin{array}{l}0 \text { Not at all } \\
1 \text { Hardly any of the time } \\
2 \text { A little of the time } \\
3 \text { A moderate amount of the time } \\
4 \text { A lot of the time } \\
5 \text { Most of the time } \\
6 \text { All the time }\end{array}$ \\
\hline $\begin{array}{l}\text { C6. On average, during (be past week, how many puffs on a short-acting } \\
\text { bronchodilator (e,g (Nentolin) have you used each day? }\end{array}$ & $\begin{array}{ll}0 & \text { None } \\
1 & 1-2 \text { puffs most days } \\
2 & 3-4 \text { puffs most days } \\
3 & 5-8 \text { puffs most days } \\
4 & 9-12 \text { puffs most days } \\
5 & 13-16 \text { puffs most days } \\
6 & \text { More than } 16 \text { puffs most days }\end{array}$ \\
\hline
\end{tabular}

\section{Q.3 How long ago were you diagnosed with asthma?}

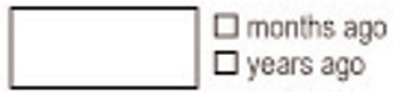

\section{Q.4 Who was it who diagnosed you with asthma?}

GP Respiratory Nurse Hospital Specialist $>$ Q.4a Which specialist?

\section{Q.5 How long after the diagnosis were you prescribed the first treatment for asthma? Immediately \\ After months}


MR Partridge et al.

Q.6 Who prescribed the first therapy to you?

GP Respiratory Nurse Hospital Specialist $\rightarrow$ Q.6a Which specialist?

Q.7 Have you ever taken the following diagnostic tests for asthma?

\begin{tabular}{|l|c|}
\hline DIAGNOSTIC TESTS & \\
\hline Peak-flow reading & Yes $\quad \square$ No \\
\hline $\begin{array}{l}\text { Spirometry (the longer breathing } \\
\text { test) }\end{array}$ & $\square$ Yes $\quad \square$ No \\
\hline Chest X-ray & $\square$ Yes $\quad \square$ No \\
\hline Skin Prick Test & $\square$ Yes $\quad \square$ No \\
\hline Blood test for allergy & $\square$ Yes \\
\hline $\begin{array}{l}\text { Other test } \\
\text { (specify }\end{array}$ & $\square$ Nes \\
\hline
\end{tabular}




\section{OTHER QUESTIONS ON THE PROCEDURES AND FREQUENCY OF VISITS TO DOCTORS}

Q.8 Since you were given the first therapy for asthma up to today, how many times have you changed your asthma therapy (including the cases when you were given a different product and when you were given additional new ones or you were removed some product)? No. of times

IF Q.8 IS GREATER THAN 0

Q.8 a How many of these changes in therapy were decided by your GP, how many by a Hospital specialist and how many by a respiratory nurse?
No. of changes
by GPs
No. of changes
by Specialist
No. of changes by respiratory Nurse

Q.9 On average, how often do you go to see a Hospital specialist for your asthma?

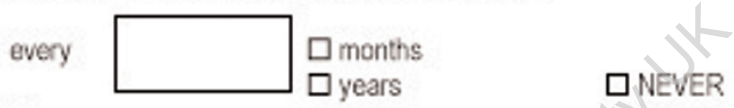

\section{IF Q.9 DIFFERENT FROM NEVER}

Q.9_a When you see the Hospital specialist for your asthma, what is the average length of the visit? Specialist: minutes

Q.10 On average, how often do you see your GP for your asthma?

IF Q.10 DIFFERENT FROM NEVER

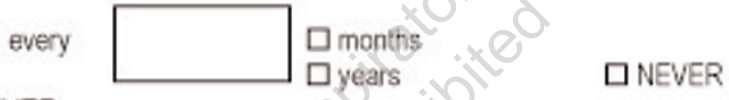

Q.10_a When you see your GP for asthma, what is the average length of the visit?

GP: minutes

Q.X On average, how often do you go to see a respiratory nurse for your asthma?

IF Q.9 DIFFERENT FROM NEVER

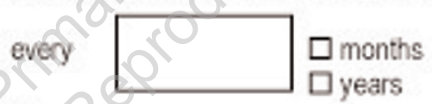

口NEVER

Q.X a When you see the respiratory nurse for your asthma, what is the average length of the visit? Respiratory nurse: minutes

Q.11 Do you know whether your GP and the specialist who follows you have had contact / have exchanged information with each other with regard to the management of your form of asthma?

YES NO DON'T KNOW

Q.12 Apart from your GPs or your specialist, are there other professional figures involved in your asthma management / treatment?

$\square$ Respiratory physiotherapist

$\square$ Chiropractor

$\square$ Other (Specity:

$\square$ No one 
MR Partridge et al.

\section{RELATIONSHIP WITH THE DOCTOR}

Q.13 How much importance do you attach to the following aspects in defining how the ideal relationship with your doctor should be for the management of asthma? Please give your answer using a scale of 1 to 10 in which $1=$ NOT AT ALL IMPORTANT and $10=$ EXTREMELY IMPORTANT

Listening carefully when I talk about my symptoms and problems Scores 1-10

Asking me lots of questions on how I feel

Understanding clearly what I am tying to express

Understanding clearly what concerns me

Explaining well what asthma is and what problems it can cause

Explaining clearly how to take the products and use the inhalers

Explaining clearly which are the possible side effects and risks of the products

Devoting an appropriate amount of time to the visit

Supporting me psychologically and preventing me being gripped by pessimism

Giving me suggestions on how to change my life style

Warning me against the dangers of asthma

Offering me support to help me manage my own condition

Emphasising the usefulness of the medicines against asthma, explaining their function

Being consulted with regard to the choice of inhaler

IF GOES TO A SPECIALIST (Q.9 different from NEVER)

Q.14 How would you define your degree of satisfaction with the relationship with your specialist with regard to the management of asthma?

$$
1=\text { Not at all satisfactory } 10=\text { Extremely satisfactory }
$$

IF GOES TO GP (Q.10 different from NEVER)

Q.15 How would you define your degree of satisfaction with the relationship with your GP with regard to the management of asthma? $1=$ Not at all satisfactory $10=$ Extremely satisfactory

Q.16 In particular, how satisfied are your with the following aspects of your relationship with your GP and with your Hospital SPECIALIST with regard to the management of your asthma? Please give your answer to both medical figures using a scale of 1 to 10 in which $1=$ NOT AT ALL SATISFACTORY and $10=$ EXTREMELY SATISFACTORY

He/She listens carefully when I talk about my symptoms and problems

Specialist GP

He/She asks me lots of questions on how I feel

$\mathrm{He} / \mathrm{She}$ understands clearly what I am trying to express

He/She understands clearly what concerns me

He/She explains well what asthma is and what problems it can cause

He/She explaining clearly how to take the products and use the inhalers

He/She explaining clearly which are the possible side effects and risks of the products

$\mathrm{He} / \mathrm{She}$ devotes an appropriate amount of time to the visit

He/She supports me psychologically and preventing me being gripped by pessimism

$\mathrm{He} / \mathrm{She}$ gives me suggestions on how to change my life style

He/She warns me against the dangers of asthma

$\mathrm{He} / \mathrm{Sh}$ offers me support to help me manage my own condition

He/She emphasises the usefulness of the medicines against asthma, explaining their function

$\mathrm{He} / \mathrm{She}$ consults me with regard to the choice of inhaler

THIS QUESTIONS WILL BE ASKED SEPARATELY FOR GPS ANO SPECIALIST

Q.17 Has your GPithe specialist ever .

- [IF SMOKER] asked you to stop smoking?

- [IF SMOKE] explained that smoking may block the effect of some medicines?

- asked you to try out the inhaler at the time he was prescribing it? 
- given you an action plan, a sheet with a set of instructions written specifically for you, telling you how and when to take your medication, what should stimulate you to take more medication (for example increased symptoms during the night), when you should start "reserve" medications and when you should seek urgent medical attention? [show the action plan on the web]

Q.18 [IF EX-SMOKER] You said that you are an ex-smoker. Did you give up smoking before or after you were diagnosed with asthma?

IF AFTER BEING DIAGNOSED at Q.18

Q.18 a As part of your treatment for asthma, had your GP / specialist asked you to give up smoking? YES NO

Q.18_b Had your GP / specialist explained that smoking may block the effect of some medicines? YES NO

If YES at 0.18 a

Q.18_c Was your decision to give up smoking made on the basis of this request by the doctor? YES NO

\section{PROPENSITY TO ACTIVELY GEN UP ON ASTHMA - SOURCES OF INFORMATION}

Q.19 How far do you, on your own initiative, seek out further information on asthma and on the new therapies for asthma?

Not at all $\quad 1$ Not very much 2 Quite a lot 3 A lot 4

Q.20 Which channels / means of information do you use or have used to do this?

- GP/Specialist

- Nurse

- Pharmacist

- Specialised magazines / Health supplements in the newspapers

- Televisioniradio programmes

Patients' associations

The Internet (Websites or specialised forums)

The Internet (non-specialised chat sites or forums: MSN, Yahoo, Google, Wikipedia, etc....)

- Other (specify)

IF selected intemet (websites or speciaised forums) at Q.19

Q20_a: Which is your favourite website?

Q.21 Has your [GP/specialist] ever:

\begin{tabular}{|l|l|l|}
\hline & \multicolumn{1}{|c|}{ GPs } & Specialist \\
\hline a) $\begin{array}{l}\text { given you written material / literature, } \\
\text { booklets or leaflets explaining the } \\
\text { condition? }\end{array}$ & $\square$ Yes \\
\hline b) recommended some websites? & $\square$ Yes $\quad \square$ No & Nos \\
\hline
\end{tabular}

\section{PERCEPTION OF THE DISEASE}

Q.22 How would you define asthma in your own words?

Q.23 Please rank the following diseases order of severity, starting from the least serious to the one you consider to be the most serious. 
MR Partridge et al.

Hypertension, Diabetes, Migraine, Arthritis, High cholestercl, asthma, Epilepsy, Parkinson, Hearth diseases, Colon-rectal cancer

Q.24 How far do you think your asthma negatively impacts the quality of your life?

$\begin{array}{llllllll}\text { Not at all } & 1 & \text { Not very much } & 2 & \text { Quite a lot } & 3 & \text { A bot } & 4\end{array}$

Q.24_a For what reasons?

Q.25 In particular, how much do you identify with each of the conditions described below?

$$
\text { SCALE: Not at all } 1 \quad \text { Not very much } 2 \text { Quite a lot } 3 \text { A lat } 4
$$

- I notably reduce my physical activity for fear of asthma attacks

- I feel embarrassed at taking the medicine in front of other people

- Ever since I have suffered from asthma I have been forced to plan all of my activities

- I control my spontaneous expressions such as laughing and shouting because of fear of an attack

- I am always afraid of not having the medicine for asthma with me

- I am always afraid of the medicine not warking when I need it to

- I am afraid of asthma worsening as the cold season comes

- I am afraid of asthma worsening as the allergic season comes

\section{PERCEPTION OF THE MEDICINES}

Q.26 How far do you associate these symbolical images with the medicine for asthma? Please use a scale of from 1 to 10 in which $1=$ "I DO NOT ASSOCIATE IT AT ALL" and 10 = "I ASSOCIATE IT VERY IAUCH INDEED".

- Opening of a window

- Transformation into Superman

- Presence of an angel friend

- Emersion of an underwater diver

- Re-entry into the atmosphere

Q.27 How far do you consider that medicines can solve the problem of asthma for patients?

Not at all 1 Not very much 2 Quite a lot 3 A lot 4

NEEDS

Q.28 Please give a score to indicate how important you think it is that the asthma medicine should possess each of the following characteristics, using a scale from 1 to 10 in which 1 = NOT AT ALL IMPORTANT and $10=$ EXTREMELY IIAPORTANT

Scores $1-10$

Efficacy in preventing the attacks before they occur

Efficacy in dealing with the attack when it occurs

Efficacy in controlling the breathing symptoms

Effective in stopping me waking me during the night

Efficacy in allowing me to practise full physical activity

Maintaining its efficacy even after long period of treatment

Speod of action

Absence of side effects

Low frequency of administration

Ease in using the inhaler

Easy portability outside the home

Being sure of having taken the medicine 
Asthma and COPD: opportunities for improved care

Asthma medicines can be for either taking as the need arises (during the attack) or for preventive purposes (and therefore need to be taken every day).

Q.29 How much do you agree with each of the following statements?

Not at all 1 Not very much 2 Somewhat 3 A lot 4

- The asthma therapy that you take every day gives me the sensation of being more ill

- The asthma therapy that you take every day does not provide any benefits that are easily felt

- The medicines that you take every day can lose their effect the longer you take them

- The asthma therapy that you take every day makes me afraid of possible side effects

- Nothing happens if one day you forget to take the daily (preventive) asthma therapy

- I manage my asthma preventive therapy in relation to how I feellon the basis of my state of health

- Preventive therapy with immediate results gives me reasons for a regular taking

\section{THERAPY AND SATISFACTION}

\section{Q.30 Are you currently taking medicines for asthma? YES NO.}

IF 'YES' AT Q 30 ASK $0.31->0.43$

Q.31 Using which products? IF YOU DON'T RECALL THEM PLEASE CHECK THE NAMES ON THE PACK.

FOREACHPRODUCT

Q.32 How many doses a day of .... (product) were you prescribed?

$1,2,3$ When I need it

IF INHALED Q.33-0.34

Q.33 Is the product .... a spray or a powder?

ONLY IF THE PRODUCT ISA SPRAY

Q.33_a Do you usually use a spacer with.......?

Q.34 How many puffs/sprays of the product ... were you prescribed for each dose? $1,2,3,4,5,6$, moce than 6

Q.35 Who prescribed your current therapy to you?

GP, Respiratory Nurse Hospital Specialist $\rightarrow$ Q.35_a Which specialist?

Q.36 How long have you been following this therapy?

[QUESTIONS Q.37-38 PER INDIVIDUAL PRODUCT]

Q.37 Using a score from 1 (not at all satisfied) to 10 (completely satisfied), how satisfied do you feel with your current therapy? Sccres 1-10

Q.38 More specifically, how do you rate, again using the scores from 1 to 10 , the therapy that you are following on the following aspects?

\footnotetext{
Efficacy in preventing the attacks before they occur

Eificacy in dealing with the attack when it occurs

Efficacy in controlling the breathing symptoms

Effective in stopping me waking me during the night

Efficacy in allowing me to practise full physical activity

Maintaining its efficacy even after long period of treatment

Speod of action

Absence of side effects

Low frequency of administration

Ease in using the inhaler

Easy portability outside the home
} 
MR Partridge et al.

Peing sure of having taken the medicine

FOR THE PREVENTIVE MEDICINES Q $39-\mathrm{Q} .42$

Q.39 In reality, people forget take a medicine that needs to be taken every day.

How many times have you forgetten to take the daily preventive asthma medicine in the last week? No. of times

If Q.39 is major of 0

Q.40 Why don't you take it?

- Because I forgot to

- Because I decided not to

- Both

Q.41 Do you use any methods to remind you to take the medicine? YES NO If "YES" at Q.41

Q.41_a What methods do you use?

Q.42 Has your GP / specialist ever given you any suggestions on how to remember to take the product every day? YES NO

Q.43 During the course of the last week how many times have you had to use the medicine as the need arose, when you had an asthma attack? IF Q.43 GREATER THAN 0

Q.43_a Which ones?

\section{COMPANIES}

Q.44 Choosing a score of from 1 (minimum) to 10 (maximum) how much trust do you have in the pharmaceutical companies?

\section{ASSOCIATIONS}

Q.45 Are you aware of the existence of asthma patient association, association of patients who help other asthma patients providing them information, education, financial support and trying to encourage the institutions to improve the care of people with asthma? YES NO

If 'YES' at $Q .45$
Q.46 Have you ever belonged to an association of asthma patients? YES NO
If "YES" at $Q .46$
Q.46_a Which one/s?

Q.47 What would the asthma patients associations have to do in order to increase your interest? 


\title{
PEOPLE WITH COPD - SURVEY
}

\author{
Gender of respondent: Male 1 Female 2 \\ introduction \\ Dear Sir / Madam,

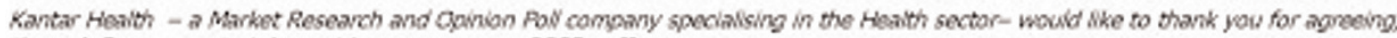 \\ through Dr. ........, to take part in ow survey an COAD sufferess \\ Are you willing to take part in the interview? YES NO \\ Whe regard to our study, please be advised thist. \\ - The answers that you give during the interview wiv remain strictly canifidentiac your name and the answers that you give wiw \\ never be divigged to third parties linking them to your nome.

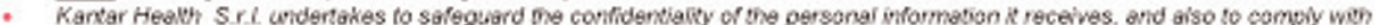 \\ the provisions of low $196 / 2003$ cancerning the handing of personal data. \\ - The party responsibie for the treatment of the data is Kantar Heach S.r. \\ How old are you? \\ Gender of respondent Male 1 Female 2 \\ Educational qualifications: Secondary School Leaver (G.C.S.E Level or equivalent) \\ Higher Education (A Level or equivalent) \\ University Degree/Diploma of equivalent
}

\section{SCREENING}

\section{S.1 Which of the following pathologies do you have?}

Asthma

Psoriasis

Hearth diseases

Diabetes

Kidney failure

COPD / Chronic-obstructive bronchitis

High Blood Pressure

Allergic rhinitis / Hay fever

Osteoporosis

Liver diseases

Gastric ulcer

Ulcerous colitis

Migraine

Anxiety / Depression

Arthritis

Parkinscn's disease

Thyroid diseases

Haemorrhoids

High cholesterol

Epilepsy 
MR Partridge et al.

\section{CLINICAL SITUATION AND HISTORY}

IF COPD

Smoker?

Current smoker

Ex-smoker

Non-smoker/Never smoked

Do you usually have the flu vaccine each year?

Yes No

Have you had the pneumoccocal vaccine in the last 5 years? Yes

No

DONT KNOW

\section{Q.1 With which of the following statements do you identify?}

- I only suffer from laboured breathing / shortness of breath aiter doing heavy jobs / physical exertion

- I suffer from laboured breathing / shortness of breath when I walk quickly or walk uphill

- I walk more slowly than other pecple of my age because of the shortness of breath I suffer when I walk

- I have to stop when walking on the level because of breathing difficulties

- I have to stop after walking 100 yards or for a few minutes because of breathing difficulties

- I wheeze too much to go out of the house or I puff and pant when I get dressed or undressed

Q.1_a How often do you happen to experience the following symptoms?

SCALE. Never, Sometimes, Quite frequently, Very frequentíy

1. Chranic coughing

2. Production of catarrh

Q.2 In the last year, how many times have you been hospitalised because of COPD / because of breathing difficulties / because you couldn't breathe? No. of times

Q.3 How long ago were you diagnosed with COPD?

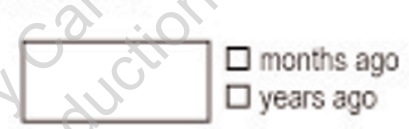

Q.4 Who was it who diagnosed you with COPD?

GP Respiratory Nurse Hospital Specialist $>$ Q.4a Which specialist?

Q.5 How long after the diagnosis were you prescribed the first treatment for COPD?

Immediately

After months

Q.6 Who prescribed the first therapy to you?

GP Respiratory Nurse Hospital Specialist -> Q.6a Which specialist? 
Asthma and COPD: opportunities for improved care

Q.7 Have you ever taken the following diagnostic tests for COPD?

\begin{tabular}{|l|c|}
\hline DIAGNOSTIC TESTS & $\square$ Yes $\square$ No \\
\hline Peak-flow reading & $\square$ Yes \\
\hline $\begin{array}{l}\text { Spirometry (the longer breathing } \\
\text { test) }\end{array}$ & $\square$ Yes $\quad \square$ No \\
\hline Chest X-ray & $\square$ Yes \\
\hline $\begin{array}{l}\text { Other test } \\
\text { (specify }\end{array}$ & No \\
\hline
\end{tabular}

OTHER QUESTIONS ON THE PROCEDURES AND FREQUENCY OF VISITS TO DOCTORS

Q.8 On average, how often do you go to see a Hospital specialist for COPD?

every

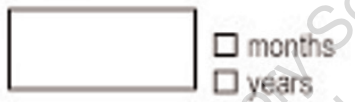

口NEVER

IF Q.8 OTHER THAN NEVER

Q.8 a When you see the Hospital specialist for COPD, what is the average length of the visit? Specialist: minutes

Q.9 On average, how often do you see your GP for COPD?

IF Q.9 OTHER THAN NEVER

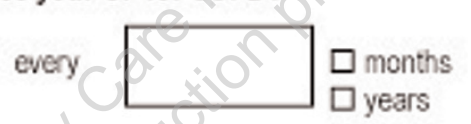

口NEVER

Q.9 a When you see your GP for COPD, what is the average length of the visit?

GP: minutes

Q.X On average, how often do you see a respiratory nurse for COPD?

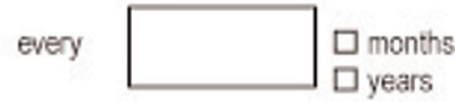

口NEVER

IF Q.9 OTHER THAN NEVER

Q.X_a When you see the respiratory nurse for COPD, what is the average length of the visit?

Respiratory nurse: minutes

Q.10 Do you know whether your GP and the specialist who follows you have had contact / have exchanged information with each other with regard to the management of your form of COPD? YES NO DON'T KNOW

Q.11 Apart from your GPs or your specialist, are there other professional figures involved in your COPD management / treatment?

$\square$ Respiratory physiotherapis!

$\square$ Chiropractor

$\square$ Other (Specity:

$\square$ No one 
MR Partridge et al.

\section{RELATIONSHIP WITH THE DOCTOR}

Q.12 How much importance do you attach to the following aspects in defining how the ideal relationship with your doctor should be for the management of COPD? Please give your answer using a scale of 1 to 10 in which $1=$ NOT AT ALL IMPORTANT and $10=$ EXTREMELY IMPORTANT

Listening carefully when I talk about my symptoms and problems

Scores 1-10

Asking me lots of questions on how I feel

Understanding clearly what I am tying to express

Understanding clearly what concerns me

Explaining well what COPD is and what problems it can cause

Explaining clearly how to take the products and use the inhalers

Explaining clearly which are the possible side effects and risks of the products

Devoting an appropriate amount of time to the visit

Supporting me psychologically and preventing me being gripped by pessimism

Giving me suggestions on how to change my life style

Warning me against the dangers of COPD

Giving me advise on how to self-treat episodes of COPD worsening

Emphasising the usefulness of the medicines against COPD, explaining their function

Being consulted with regard to the choice of inhaler

Not being made to feel guily about the style of life that I lead / that I have led

IF GOES TO A SPECIALIST \{Q 8 different from NEVER\}

Q.13 How would you define your degree of satisfaction with the relationship with your specialist with regard to the management of COPD? $1=$ Not at all satisfactory $10=$ Extremely satisfactory

IF GOES TO GP (Q.9 different from NEVER)

Q.14 How would you define your degree of satisfaction with the relationship with your GP with regard to the management of COPD? $1=$ Not at all satisfactory $10=$ Extremely satisfactory

Q.15 In particular, how satisfied are you with the following aspects of your relationship with your GP and with your Hospital SPECIALIST with regard to the management of COPD? Please give your answer answer to both medical figures using a scale of 1 to 10 in which $1=$ NOT AT ALL SATISFACTORY and $10=$ EXTREMELY SATISFACTORY

He/She listens carefully when I talk about my symptoms and problems

$$
\text { Specialist GP }
$$

He/She asks me lots of questions on how I feel

He/She understands clearly what I am trying to express

He/She understands clearly what concerns me

$\mathrm{He} / \mathrm{She}$ explains well what COPD is and what problems it can cause

He/She explains clearly how to take the products and use the inhalers

He/She explains clearly which are the possible side effects and risks of the products

He/She devotes an appropriate amount of time to the visit

He/She supports me psychologically and preventing me being gripped by pessimism

He/She gives me suggestions on how to change my life style

He/She warns me against the dangers of COPD

He/She gives me advise on how to self-treat episodes of COPD worsening

He/She emphasises the usefulness of the medicines against COPD, explaining their function

He/She consults me with regard to the choice of inhaler

He/She doesn't blame me about the style of life that I lead / that I have led

THIS QUESTIONS WILL BE ASKED SEPARATELY FOR GPS AND SPECIALIST

Q.16 Has your [GPithe specialist] ever .......

a) [iF SMOKER] asked you to stop smoking? 
b) asked you to try out the inhaler at the time he was prescribing it?

c) given you an action plan, a sheet with a set of instructions written specifically for you, telling you how and when to take your medication, what should stimulate you to take more medication (for example increased symptoms during the night), when you should start "reserve" medications and when you should seek urgent medical attention? [show the action plan on the web]

Q.17 [IF EX-SMOKER] You said that you are an ex-smoker. Did you give up smoking before or after you were diagnosed with COPD? BEFORE AFTER

IF AFTER BEING DIAGNOSED at Q.17

Q.17_a As part of your treatment for COPD, had your GP / specialist asked you to give up smoking? YES NO

If YES at Q.17_a

Q.17_b Was your decision to give up smoking made on the basis of this request by the doctor? YES NO

\section{PROPENSITY TO ACTIVELY GEN UP ON COPD - SOURCES OF INFORMATION}

Q.18 How far do you, on your own initiative, seek out further information on COPD and on the new therapies for COPD?
Not at all
$1 \quad$ Not very much
2 Quite a lot
A lot 4

Q.19 Which channels / means of information do you use or have used to do this?

- GP / Specialist

- Nurse

- Pharmacist

- Specialised magazines / Health supplements in the newspapers

- Televisioniradio programmes

- Patients associations

- The Internet (Websites or specialised forums)

- The Internet (non-specialised chat sites or forums: MSN, Yahoo, Google, Wikipedia, etc....)

- Other (specify).

IF selected internet (websites or specialised forums at Q.19

Q19_a: Which is your favourite website?

Q.20 Has your [GPispecialist] ever:

\begin{tabular}{|l|l|l|}
\hline & \multicolumn{1}{|c|}{ GPs } & Specialist \\
\hline a) $\begin{array}{l}\text { given you written material / literature, } \\
\text { booklets or leaflets explaining the } \\
\text { condition? }\end{array}$ & $\square$ Yes \\
\hline b) No & $\square$ Yes \\
\hline recommended some websites? & $\square$ Yes $\square$ No \\
\hline
\end{tabular}

\section{PERCEPTION OF THE DISEASE}

Q.21 How would you define COPD in your own words?

Q.22 Please rank the following diseases order of severity, starting from the least serious to the one you consider to be the most serious. 
MR Partridge et al.

Hypertension, Diabetes, Migraine, Arthritis, High cholesterol, Epilepsy, COPD, Asthma, Parkinson, Hearth diseases, Colon-rectal cancer

Q.23 How far do you think COPD negatively impacts the quality of your life?

$\begin{array}{lllllll}\text { Not at all } & 1 & \text { Not very much } & 2 & \text { Quite a lot } & 3 & \text { A bot } 4\end{array}$

Q.23_a For what reasons?

Q.24 In particular, how much do you identify with each of the conditions described below?

$$
\text { SCALE: Not at all } 1 \quad \text { Not very much } 2 \text { Quite a lot } 3 \quad \text { A lot } 4
$$

- I notably reduce my physical activity for fear of breathing difficulties

- Breathing is no longer a natural acticn but an effort

- I feel embarrassed at taking the medicine in front of other people

- Ever since I have suffered from COPD I have been forced to plan all of my activities

- I am always alraid of not having the medicine for COPO with me

- I am always afraid of the medicine not working when I need it to

- I have the sensation that my situation is getting worse all the time

- Because of COPD I feel I am a burden on the rest of my family

- Because of COPD I have lost my independence

- Because of COPD I have difficulty in walking up the stairs or walking

- Because of COPD I don't go cut any more

- I am afraid of COPD worsening as the cold season comes

\section{PERCEPTION OF THE MEDICINES}

Q.25 How far do you associate these symbolical images with the medicine for COPD? Please use a scale of from 1 to 10 in which 1 = "I DO NOT ASSOCIATE IT AT ALL" and $10=$ "I ASSOCIATE IT VERY MUCH INDEED".

- A key that opens a padlock

- A parachute that opens

- An instrumentitool that makes it possible to go furtherffaster

- Presence of an angel friendiguardian angel

\section{Q.26 How far do you consider that medicines can solve the problem of COPD for patients?}

Not at all 1 Not very much 2 Quite a lot 3 A bot 4

NEEDS

Q.27 Please give a score to indicate how important you think it is that the COPD medicine should possess each of the following characteristics, using a scale from 1 to 10 in which 1 = NOT AT ALL IMPORTANT and $10=$ EXTREIAELY IMAPORTANT

Efficacy in avoiding the need to go to hospital for breathing problems

Scores 1-10

Efficacy in clearing up the breathing difficulty when it occurs

Efficacy in avoiding waking up during the night

Efficacy in reducing breathlessness

Maintenance of the efficacy even after long period of treatment

Speed of action

Lack of side effects

Low frequency of administration

Ease in using the inhaler

Easy portability outside the home

Being sure of having taken the medicine

Possibility of stopping the disease getting worse 
Asthma and COPD: opportunities for improved care

Making walking, walking up the stairs or getting dressed less effortful

Being able to perform my normal everyday activities

COPD medicines can be for either taking as the need arises (when the shortness of breath occurs) or for preventive purposes (and therefore need to be taken every day).

Q.28 How much do you agree with each of the following statements?

SCALE: Not at all 1 Not very much 2 Quite a lot 3 Alot 4

- The therapy for COPD that you take every day gives me the sensation of being more ill

- The therapy for COPD that you take every day does not provide any benefits that are easily felt

- The medicines that you take every day can lose their effect as time goes by

- The therapy for COPD that you take every day makes me afraid of possible side effects

- Nothing happens if one day you forget to take the COPD for preventive purposes

- I manage my COPD preventive therapy in relation to how I feelion the basis of my state of health

- I might sometimes take larger doses of the medicine than those prescribed in order to be easier in my mind

- Preventive therapy with immediate results gives me reasons for a regular taking

\section{THERAPY AND SATISFACTION}

Q.29 Are you following any of the following therapies?

- Pulmonary Rehabilitation (a four to six week course which involves exercise training, dietary advice, self management education and information about the treatments for your condition)

- Long-term oxygen therapy

YES

NO

Q.30 Are you currently taking medicines for COPD?

IF "YES" AT Q.30 ASK Q.31-> Q.43

Q.31 Using which products? IF YOU DON'T RECALL THEM PLEASE CHECK THE HAMES ON THE PACK.

\section{FOREACHPROOUCT}

Q.32 How many doses a day of .... (product) were you prescribed?

$1,2,3$ When I need it

IF INHALED Q.33-Q 34

Q.33 Is the product .... a spray or a powder?

ONLY IF THE PRODUCT IS A SPRAY

Q.33 a Do you usually use a spacer with........?

Q.34 How many puffs of the product ... Were you prescribed for each administration? $1,2,3,4,5,6$, more than 6

Q.35 Who prescribed your current therapy to you?

GP. Respiratory Nurse Hospital Specialist $\rightarrow$ Q.35 a Which specialist?

Q.36 How long have you been following this therapy?

[QUESTIONS Q 37-38 FOR INDIVIDUAL PRODUCT]

Q.37 Using a score from 1 (not at all satisfied) to 10 (completely satisfied), how satisfied do you feel with your current therapy? Scores 1-10

Q.38 More specifically, how do you rate, again using the scores from 1 to 10 , the therapy that you are following on the following aspects? 
MR Partridge et al.

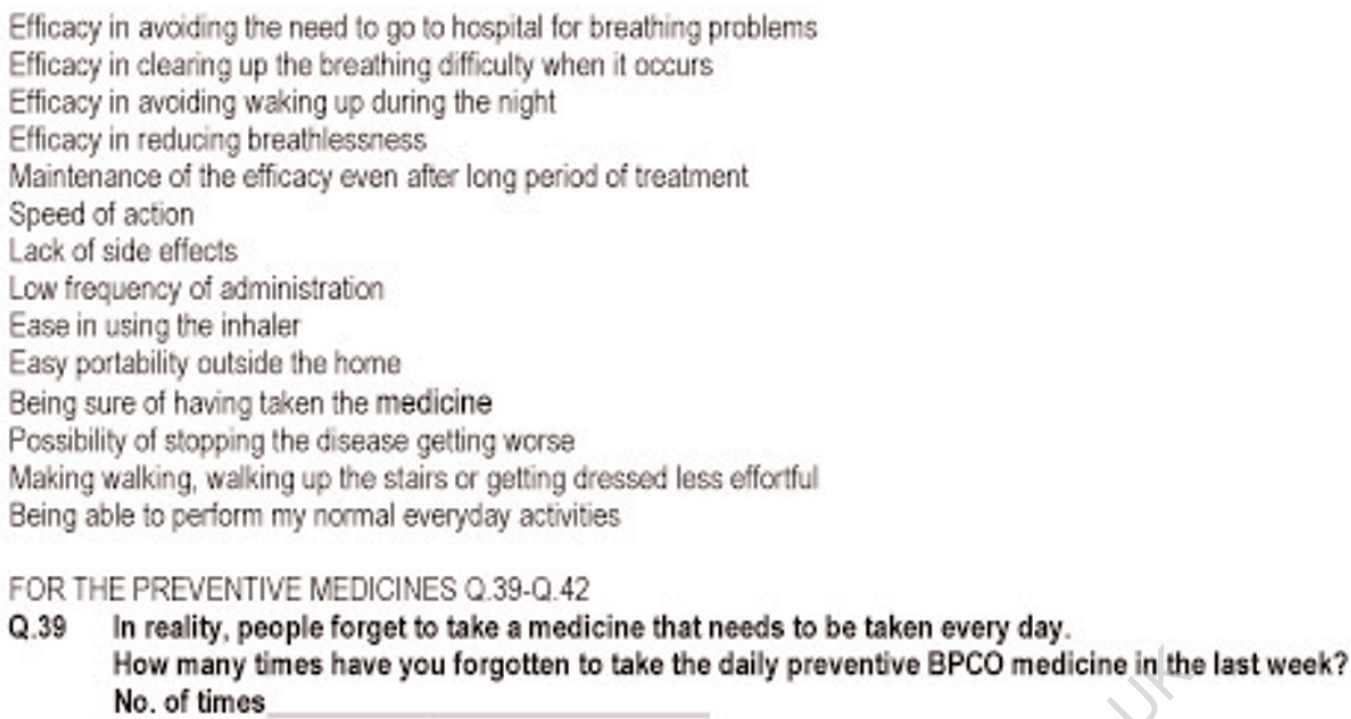

If $Q .39$ is major of 0

Q.40 Why don't you take it?

- Because I forget to

- Because I decided not to

- Both

Q.41 Do you use any methods to help you to remember to take the medicine? YES

NO If "YES" at Q.41

Q.41 a What methods?

Q.42 Has your GP/ specialist ever given you any suggestions on how to remember to take the product every day? $\quad$ YES

Q.43 During the course of the last week how many times have you had to use the medicine as the need arose, to deal with breathing difficulties?

If Q.43 MORE THAN 0

D.43_a Which ones?

\section{COMPANIES}

Q.44 Choosing a score of from 1 (minimum) to 10 (maximum) how much trust do you have in the pharmaceutical companies?

\section{ASSOCIATIONS}

Q.45 Are you aware of the existence of COPD patient association, association of patients who help other COPD patients providing them information, education, financial support and trying to encourage the institutions to improve the care of people with COPD? YES NO

If 'YES' at $Q .45$

Q.46 Have you ever belonged to an association of COPD patients? YES NO

If 'YES' at 0.46

Q.46_a Which one/s?

Q.47 What would the COPD patients associations have to do in order to increase your interest? 